\title{
QUEEN'S
UNIVERSITY
BELFAST
}

\section{Does grouping environmental enrichments together affect the way they are used by commercially housed broiler chickens?}

Baxter, M., \& O'Connell, N. E. (2018). Does grouping environmental enrichments together affect the way they are used by commercially housed broiler chickens? Applied Animal Behaviour Science, 210, 52-59. https://doi.org/10.1016/j.applanim.2018.10.017

Published in:

Applied Animal Behaviour Science

Document Version:

Peer reviewed version

Queen's University Belfast - Research Portal:

Link to publication record in Queen's University Belfast Research Portal

\section{Publisher rights}

Copyright 2018 Elsevier.

This manuscript is distributed under a Creative Commons Attribution-NonCommercial-NoDerivs License

(https://creativecommons.org/licenses/by-nc-nd/4.0/), which permits distribution and reproduction for non-commercial purposes, provided the author and source are cited.

\section{General rights}

Copyright for the publications made accessible via the Queen's University Belfast Research Portal is retained by the author(s) and / or other copyright owners and it is a condition of accessing these publications that users recognise and abide by the legal requirements associated with these rights.

Take down policy

The Research Portal is Queen's institutional repository that provides access to Queen's research output. Every effort has been made to ensure that content in the Research Portal does not infringe any person's rights, or applicable UK laws. If you discover content in the Research Portal that you believe breaches copyright or violates any law, please contact openaccess@qub.ac.uk. 


\section{Does grouping environmental enrichments together affect the way they are used by commercially housed broiler chickens? \\ Mary Baxter* and Niamh E. O'Connell}

Institute for Global Food Security, Queens University Belfast, 18-30 Malone Road, Belfast, Northern Ireland, BT9 5BN.m.baxter@qub.ac.uk.

${ }^{*}$ Corresponding author. email: $\underline{\text { m.baxter@qub.ac.uk }}$

\section{Abstract}

Identifying the most attractive ways of presenting environmental enrichments in commercial broiler housing may encourage use and optimise their effectiveness. This study investigated the effect of grouping straw bales (SB), oat hulls $(\mathrm{OH}$; as a dustbathing substrate) and pecking chain $(\mathrm{Pe})$ together, compared to providing individual enrichments, on level of enrichment use and the behaviour of proximate broilers. Approximately 56000 Ross 308 broiler chickens were placed in two matched commercial houses on one farm (max. 30 $\mathrm{kg} / \mathrm{m}^{2}$ ). On day $4, \mathrm{SB}, \mathrm{OH}$ (in steel rings 1.1 diameter, $7.62 \mathrm{~cm}$ deep), and black/yellow plastic Pe were introduced. These enrichments were grouped into seven enrichment combinations per house: 1) $\mathrm{SB}$ only, 2) $\mathrm{OH}$ only, 3) $\mathrm{Pe}$ only, 4) $\mathrm{SB}+\mathrm{OH}$, 5) $\mathrm{SB}+\mathrm{Pe}, 6$ ) $\mathrm{OH}+\mathrm{Pe}$, and 7) $\mathrm{SB}+\mathrm{OH}+\mathrm{Pe}$. The farm was visited twice weekly over one production cycle in weeks 2, 3, 4 and 5. Behavioural data was collected using scan and focal sampling from video footage. Each enrichment type was compared with its three alternative combinations. In general, level of use of $\mathrm{SB}$ and $\mathrm{OH}$ was similar to previous research, but use of $\mathrm{Pe}$ was higher than anticipated. Enrichment combination did not have a significant effect on the number of broilers around the straw bales or in the oat hull rings, or on the types of behaviours observed. Focal observations of direct enrichment use revealed that significantly more vertical wingshakes were performed when the oat hulls were placed singly $(\mathrm{OH})$ rather than in the $\mathrm{SB}+\mathrm{OH}+\mathrm{Pe}$ combination $(P=0.026)$. There was a significant interaction between enrichment combination and week for the number of pecks directed at the straw bales $(P=$ 0.013), and no effect of enrichment combination on the number of pecks directed at the pecking chain $(P>0.05)$. Specific effects of placing SB close to $\mathrm{OH}$ (as a possible form of 
vertical cover) on levels of dustbathing and disturbance was examined, but no significant effects were found. In conclusion, we found no obvious benefits to grouping these enrichments together rather than providing them singly, and some practical benefits to placing enrichments individually (such as more even distribution of fresh straw throughout the house). Straw bales did not appear to offer significant protective cover around dustbathing areas, with no increase in comfort behaviours or reduction in disturbances observed. Broilers were substantially more interested in pecking chain than has been previously reported, highlighting the need for more commercial scale research.

\section{Highlights:}

- Grouping enrichments did not attract more birds to use enrichments

- The majority of behaviours observed were unaffected by grouping enrichments

- More vertical winshaking was observed in singly placed dustbathing areas

- Straw bales did not appear to offer protective cover around dustbathing areas

- Broilers showed significant interest in a pecking enrichment 


\section{Introduction}

Environmental enrichment is being increasingly used to provide farm animals with more complex and engaging environments. Introducing resources that provide stimulation and improve the biological functioning of animals (Newberry, 1995) can lead to a reduction in abnormal behaviours (D'eath et al., 2014; Tahamtani et al., 2016) and improvements in production and well-being (El-Lethey et al., 2000; Douglas et al., 2012). For broilers, environmental enrichments are usually designed to encourage the performance of natural behaviours, including foraging and perching, and to increase their low activity levels. The majority of higher welfare broiler housing contains some combination of perches, straw bales, and/or pecking objects (CIWF, 2017). Straw bales are primarily used by broilers as protected rest areas in commercial housing, however they also stimulate natural foraging behaviour and broilers will peck at and dismantle short-cut bales (Baxter et al., 2018). There have been very few studies looking at the use of pecking enrichments in commercial broilers, with a low level of interest previously reported in penned broilers (Arnould et al., 2004). However, a recent study found that broilers in commercial housing would regularly peck at bunches of string (Bailie and O'Connell, 2015), suggesting a pecking stimulus may be a suitable enrichment.

Under commercial conditions, environmental enrichments tend to be distributed evenly throughout the large houses. As little is known about the home ranges of commercial broilers, this spread of enrichments increases the likelihood that birds will encounter and benefit from these additions. However, animals will show greater interaction with their environment when their surroundings are complex rather than simple (Chamove, 1989), and broilers are motivated to explore areas containing a variety of enrichments (a straw bale, peat, a platform and a ramp; Newberry, 1999). In addition, laying hens will peck more readily at three pecking stimuli when offered simultaneously rather than individually (Jones et al., 2000). It was therefore hypothesised that grouping enrichments together rather than 
presenting them singly would attract a higher number of birds to the area and result in a higher level of enrichment use.

Although dustbathing substrates have not been widely introduced to commercial housing, several recent studies have shown that broilers will readily perform dustbathing in a loose, friable substrate such as peat or oat hulls (Baxter et al., 2017; Baxter et al., 2018). Broilers also showed increased use of dustbathing substrate with age (Baxter et al., 2017; Baxter et al., 2018), indicating that it would be an attractive enrichment throughout their production cycle. Chickens also showed more dustbathing behaviour when in the presence of a pecking enrichment (Guy and Wright, 2003), which suggests grouping a dustbathing substrate with other enrichments may increase its use. Although dustbathing substrates in previous experiments have been placed in open areas of the commercial house (Baxter et al., 2017; Baxter et al., 2018), broilers will perform more dustbathing, resting and preening in the presence of vertical cover (Cornetto and Estevez, 2001). When grouped next to a vertical structure, broilers are also less likely to be jostled and disturbed by conspecifics (Cornetto et al., 2002), which could otherwise approach from all directions (Buijs et al., 2010). As straw bales appear to be perceived as protective cover for resting (Kells et al., 2001; Baxter et al., 2018), we also hypothesised that grouping straw bales around dustbathing areas may provide cover to broilers, which would result in higher levels of dustbathing and fewer disturbances.

Therefore, this experiment was designed to investigate whether grouping straw bales, pecking objects and dustbathing areas of oat hulls in various combinations would attract more broilers to the enrichments, alter the behaviours performed around each enrichment, and increase the levels of direct use of each enrichment. This trial was conducted in commercial housing in order to better understand the practicality of this method. 


\section{Materials and Methods}

\subsection{Animals and Housing}

This trial was conducted in two matched houses on a Northern Ireland commercial farm between May and July 2017. Approximately 28000 Ross 308 broiler chickens were placed "as hatched" in each house on the same day, giving an average 50:50 female to male ratio. The houses were matched for design and size; both were $85 \mathrm{~m} \times 20 \mathrm{~m}$ metal framed sheds, with an average usable floor space of $\sim 1716 \mathrm{~m}^{2}$. Birds were housed at a maximum stocking density of $30 \mathrm{~kg} / \mathrm{m}^{2}$, which was the standard for this farm. The houses were initially bedded on fresh woodshavings and additional woodshavings were distributed throughout to maintain litter condition at the farmer's discretion. Temperature and humidity were maintained to commercial standards (Aviagen, 2014) and were identical between the two houses. Ventilation consisted of ceiling fans and wall flaps along the two long sides of the houses. The fans and flaps operated automatically if temperature or humidity fell outside the optimal for that week, and could be adjusted manually in response to changes in bird behaviour. Both houses were heated using identically placed large hot water heaters along the central line of the house. A commercial starter, grower and finisher feed was provided ad libitum to the birds across the cycle (Aviagen, 2014) and water was supplied in nipple drinker lines. Houses were windowed and natural light was supplied in addition to fluorescent strip lighting; the lighting regime followed normal practice for this commercial supplier, with the hours of darkness increasing from 1 hour at a day old to 6 hours by day 7 , maintaining this regime until day 29 when hours of darkness gradually reduced to 1 hour by day 33 , which was maintained until slaughter. The dark period began at $11 \mathrm{pm}$, and was maintained from $11 \mathrm{pm}-$ 5am between days 7 and 29. Window shutters were controlled automatically using timers, to open at 9am and close at sunset. A portion of birds were removed for slaughter on day 36, and the remaining birds were cleared for slaughter on day 42 , as was normal practice.

\subsection{Treatments}


Seven enrichment combinations were placed in each house (Figure 1): 1) individual straw bales only (SB), 2) individual oat hulls rings only $(\mathrm{OH}), 3)$ pecking chains only $(\mathrm{Pe}), 4)$ straw bales and pecking chains $(\mathrm{SB}+\mathrm{Pe}), 5)$ oat hulls and pecking chains $(\mathrm{OH}+\mathrm{Pe}), 6)$ straw bales and oat hulls $(\mathrm{SB}+\mathrm{OH}), 7)$ straw bales and oat hulls and pecking chains $(\mathrm{SB}+\mathrm{OH}+\mathrm{Pe}$; Photo 1). All enrichments were placed on day 4 of the cycle to avoid disrupting chick feeder sheets. Enrichment location was chosen using restricted randomisation, with the condition that enrichment areas should be evenly placed in back and front areas of the houses. All enrichments were equidistant from the nearest windows to control for the influence of natural light intensity. Straw bales were plastic wrapped, short cut straw bales that were used as standard enrichment bales on the farm. Three bales were placed in an L-shape which created a semi-enclosed area (Photo 1). As per normal management practices, the two long sides of the bales were cut open to allow birds to peck out the straw. For the purposes of this trial, once the top of a bale collapsed it was replaced in the same location with a new bale. Oat hulls are the by-product of oat processing and were locally sourced (Whites Speedicook Ltd, Craigavon, UK). The outer hulls are ground and have a consistency and colour similar to fine sawdust. They have previously been found to promote dustbathing and foraging in broilers (Baxter et al., 2017; 2018) and would be a commercially practical substrate. Oat hulls were provided in one steel ring per area; steel rings had a $1.1 \mathrm{~m}$ diameter and were $7.62 \mathrm{~cm}$ deep, with an area of $0.95 \mathrm{~cm}^{2}$. Birds were able to climb into the rings from day 4 and were unable to perch on the edges. Approximately $14 \mathrm{~kg}$ of oat hulls was initially placed in the rings, filling them to a depth of about $5 \mathrm{~cm}$. All rings were topped up twice a week on the morning of observations to their original level throughout the trial. During weeks 4 and 5 , oat hulls were also refilled on an additional day between observations to maintain their condition as the oat hulls degraded more rapidly in later weeks. The pecking chain provided was $8 \mathrm{~mm}$ black and yellow plastic-coated barrier chain, cut to lengths of approximately 30 cm (AIMTools Ltd, UK). Yellow has previously been found to be an attractive pecking colour to chickens (Jones and Carmichael, 1998; Jones et al, 2000). The chain was hung from the feeder lines, in three sections with two hanging chains per section, opposite the single bale 
in the enrichment area (Photo 1). The chains hung approximately $0.4 \mathrm{~m}$ from the edge of the oat hull rings, if present, and varied in distance from each straw bale (Photo 1). In areas with both straw bales and oat hulls, oat hull rings were approximately $0.5 \mathrm{~m}$ from the edge of the bales.

\subsection{Data Collection}

Both houses were visited twice a week during weeks 2, 3, 4 and 5 of the production cycle. Video footage of bird behaviour around each enrichment was taken between 09:00 $\mathrm{h}$ and 13:00 h, and measures of disturbance and light intensity were completed between 13:00 h and 16:00 h each day.

Toshiba Camileo X-Sports cameras, mounted on 1 metre high wooden tripods, were used to record enrichment areas. Both houses were filmed on the same day. The footage was then analysed by the same observer using a combination of scan sampling and focal observations. For straw bales, the two adjacent bales in all four locations were filmed on both sides simultaneously for 35 minutes, using eight cameras. Following a 5 minute settling period, birds directly in front of the bales (up to $0.4 \mathrm{~m}$ distance from the bales, measured as the height of the bale virtually transposed onto the house floor in front of the adjacent bales) were scan sampled at 10, 20 and 30 minutes of each video (a total of 384 scans). As in Baxter et al. (2018), all birds in the area around the bales were recorded as either sitting inactive (sitting or resting with no other activity), sitting pecking, foraging, dustbathing, locomotion (walking or standing), or preening (sitting or standing). The three scan samples were averaged to give the mean number of birds performing each behaviour in proximity to the two bales. Scores for the two sides of the bales were summed to give a total score for the two sides of the bales, and the average number of birds performing each behaviour was then expressed as a percentage of the total number of birds around the bales. The bi-weekly observations were then averaged to give one value per week. Once per week, footage of 
each of the two bales was also observed for a 10 minute focal period (following a 10 minute settling period). The number of pecks directed at exposed straw on the side of the bales facing the inner area of the L-shape (facing towards other enrichments, if present) was recorded and values for the two bales summed, to give a score of the number of pecks directed at the inner side of two bales.

Oat hulls were similarly filmed for 35 minutes in each location, using one camera set up next to each of the four rings. Each video was analysed using scan sampling to assess behaviour in the oat hulls, and focal sampling to measure the amount of dustbathing. For each video, scan sampling was performed in the same manner as around bales, with scans of bird behaviour taken at 10, 20 and 30 minutes after a 5 minute settling period. The three scans were then averaged to give the mean number of birds performing each behaviour, and the bi-weekly scores averaged to give one score per week. For focal observations performed once per week, following a 10 minute settling period, the number of vertical wing shakes performed in the oat hulls was counted during a 20 minute focal period as a measure of the amount of dustbathing performed (e.g. Sanotra et al, 1995). The mean length of a dustbathing bout in oat hulls is 14 minutes (SEM 0.85), with an average of 23 vertical wingshakes (Baxter et al., 2017). This length of focal observation was chosen in order to observe a number of complete dustbathing bouts.

Pecking chain areas were filmed for a total of 25 minutes each, using four camera tripods placed next to the chains (facing towards to house wall). Due to the rapid nature of any engagement with pecking chains, only focal sampling was performed on pecking chain footage. Once a week, after a 5-minute settling period, the number of pecks directed at the three pecking chains per area was counted for a 10 minute focal period.

To assess whether bales act as cover for birds using oat hulls, a separate measure of disturbance was taken by direct observation each week. The number of disturbance events was counted in birds in stand-alone oat hull rings $(\mathrm{OH})$ and in oat hull rings surrounded by bales $(\mathrm{SB}+\mathrm{OH})$. The same observer sat approximately 2 metres from the ring in both cases 
and, after a 5 minute settling period, recorded any incidences of disturbance for the following 10 minutes. An incidence of disturbance was recorded when a bird made physical contact with another bird, causing it to stand (Estevez, 1994). During the focal period, the number of birds in the ring was counted every minute, and the 10 scores were averaged to give the mean number of birds present in the ring during the observation period. This additional measure of ring occupancy was taken to allow direct comparison with disturbance events, in order to better understand the relationship between bird density in the rings and disturbance. The number of disturbance events recorded and the number of birds recorded in the ring were averaged to give one score per week.

Light levels were automatically maintained, however measures of light (lux meter) were taken from all enrichment areas in both houses, no more than 5 minutes apart, to monitor variation and avoid light as a confounding variable.

\section{Statistics}

Data were analysed using SPSS (version 23). Due to the scale of the study and limited use of the commercial farm, only two houses were used in this trial over one production cycle, resulting in two replicates. Eight enrichment combinations were placed evenly around House 1 and around House 2 using restricted randomisation, with the condition that in one replicate the enrichment combination should be at the front of the house, and in the back of the house in the second replicate (Figure 1). For each enrichment type, the four levels of enrichment combination were compared with each other; for example, data for oat hulls were compared between 1) individual oat hulls, 2) oat hulls and pecking chain, 3) oat hulls and straw bales and 4) oat hulls, straw bales and pecking chain. Normality of residuals was assessed for each data set through inspection of normality plots and Shapiro-Wilk tests. Significance level was set at $P<0.05$. Post-hoc pairwise comparisons were performed using Tukey HSD tests $(P<0.05)$. 
For observations of mean occupancy $(n=32)$ and the mean percent of behaviours $(n=32)$ performed around the bales and in the oat hulls, the main and interaction effects of treatment and week were analysed using GLM, with enrichment combination + week as fixed effects, and house.week as a random factor. Data from focal samples on the number of VWS performed in oat hulls $(n=32)$, the number of pecks directed at bales $(n=32)$, and the number of pecks directed at pecking chain $(n=32)$ were analysed using the same model. Light intensity $(n=112)$ was compared between the seven enrichment areas using GLM with enrichment combination as a fixed factor and house as a random factor, and between the two houses using a one-way ANOVA. There was no significant difference in ring occupancy between $\mathrm{OH}$ and $\mathrm{SB}+\mathrm{OH}$ during focal observations of disturbance $(P>0.05)$, therefore disturbance was analysed using a GLM with enrichment combination as a fixed factor and house as a random factor $(n=16)$. A Pearson product-moment correlation coefficient was calculated to investigate the linear relationship of average birds in the ring and the number of disturbances recorded.

\section{Results}

There was no significant difference in light intensity between enrichment combinations or between houses $(P>0.05)$. Light intensity was therefore disregarded as a source of variation.

\subsection{Straw Bales}

Whether bales were placed singly or in combination with other enrichments did not have a significant effect on the total number of birds counted around the bales. Overall, there was an average of 30 (SE = 1.1) birds counted around the two bales, with fewer birds counted around the bales as birds aged $\left(F_{3,3}=17.46, P=0.009\right)$, which was expected because the observation area was fixed so fewer birds fit within the scan area. Although there was minimal dustbathing performed around the straw bales $(\mathrm{M}=0.3 \%, \mathrm{SE}=0.10)$, there was a significant interaction between enrichment combination and week $\left(F_{9,12}=2.92, P=0.043\right)$. 
Simple effects analysis showed that the broilers age had a significant effect on the amount of dustbathing performed in the $\mathrm{SB}+\mathrm{OH}$ (week $2, \mathrm{M}=0 \%$; week $3, \mathrm{M}=0 \%$; week $4, \mathrm{M}=1.1 \%$; week $5, \mathrm{M}=1.1 \%$ ) and $\mathrm{SB}+\mathrm{OH}+\mathrm{Pe}($ week $2, \mathrm{M}=0 \%$, week $3, \mathrm{M}=0.3 \%$, week $4, \mathrm{M}=1.5 \%$, week $5, M=0 \%$ ) but not the SB (week $2, M=0 \%$; week $3, M=0.26 \%$; week $4, M=0 \%$; week $5, M=0 \%$ and $S B+P e$ combinations (week 2, $M=0 \%$; week 3, $M=0.81 \%$; week 4, $M$ $=0 \%$; week $5, M=0.34 \%)$. There was no significant effect of enrichment combination on percentage of broilers sitting inactive, sitting pecking, foraging, preening or in locomotion around the bales (Table 1), and no significant interactions between combination and week. There was, however, a main effect of age on the $\%$ of sitting pecking around the bales $\left(\mathrm{F}_{3,4}=\right.$ $6.66, P=0.049$ ), with significantly more sitting pecking observed in week 2 compared to week 5 (week 2, $M=14.1 \%, S E=1.02$; week $3, M=11.8 \%$, SE $=5.13$; week $4, M=8.1 \%$, SE $=1.34 ;$ week $5, M=5.6 \%, S E=0.69)$.

During the 10 minute focal period, there were an average of 310 (SE $=18.8$ ) pecks directed at the straw bales (Figure 2). There was a significant interaction between enrichment combination and week for the average number of bale pecks $\left(F_{9,12}=4.08, P=0.013\right)$. Average bale pecking was significantly affected by enrichment combination in weeks 2 and 4 , with higher levels of pecking at the $\mathrm{SB}$ compared to the $\mathrm{SB}+\mathrm{OH}+\mathrm{Pe}$ combination in week $2(\mathrm{SB}, \mathrm{M}=451.0, \mathrm{SE}=18.0 ; \mathrm{SB}+\mathrm{OH}, \mathrm{M}=278.0, \mathrm{SE}=50 ; \mathrm{SB}+\mathrm{Pe}, \mathrm{M}=395.5, \mathrm{SE}=3.65$; $\mathrm{SB}+\mathrm{OH}+\mathrm{Pe}, \mathrm{M}=207.0, \mathrm{SE}=0.98)$, and higher levels of pecking in the $\mathrm{SB}+\mathrm{Pe}$ combination compared to $\mathrm{SB}+\mathrm{OH}$ in week $4(\mathrm{SB}, \mathrm{M}=309.5, \mathrm{SE}=122.5 ; \mathrm{SB}+\mathrm{OH}, \mathrm{M}=133.5, \mathrm{SE}=43.5$; $\mathrm{SB}+\mathrm{Pe}, \mathrm{M}=375.0, \mathrm{SE}=47.0 ; \mathrm{SB}+\mathrm{OH}+\mathrm{Pe}, \mathrm{M}=325.0, \mathrm{SE}=118.0)$.

\subsection{Oat Hulls}

Overall, an average of 11 birds were counted in the oat hull rings; the birds age did not affect how many birds were present in the rings $(P>0.05)$. Whether the oat hulls were placed singly or in combination with other enrichments similarly did not have a significant effect on the total number of birds in the rings or the percentage of any behaviours performed $(P>$ 0.05 ; Table 1). There was a significant effect of broiler age on the percentage of birds 
dustbathing $\left(F_{3,4}=14.44, P=0.013\right)$, with levels of dustbathing increasing as birds aged (week $2, M=9.2 \%, S E=1.56$; week $3, M=17.7 \%, S E=6.8$; week $4, M=27.2 \%, S E=$ 2.20; week $5, M=31.9 \%, S E=4.29$ ). There was also an overall effect of age on the percentage of broilers sitting inactive in the rings, with the most inactivity recorded in week 5 $\left(F_{3,4}=10.66, P=0.022\right.$; week $2, M=27.6 \%, S E=2.01$; week $3, M=31.0 \%, S E=3.19$; week $4, \mathrm{M}=21.7 \%, \mathrm{SE}=2.81$; week $5, \mathrm{M}=31.4 \%, \mathrm{SE}=1.31 \%)$.

There was an average of $74(\mathrm{SE}=8.43)$ vertical wingshakes per 20 minute focal period. Enrichment combination had a significant effect on the number of vertical wingshakes performed $\left(F_{3,12}=4.44, P=0.026\right)$, with significantly more vertical wingshakes performed in the $\mathrm{OH}$ only compared to $\mathrm{SB}+\mathrm{OH}+\mathrm{Pe}$ areas $(\mathrm{OH}, \mathrm{M}=93.6, \mathrm{SE}=19.86 ; \mathrm{OH}+\mathrm{Pe}, \mathrm{M}=71.1$, $\mathrm{SE}=14.96 ; \mathrm{SB}+\mathrm{OH}, \mathrm{M}=87.6, \mathrm{SE}=11.82 ; \mathrm{SB}+\mathrm{OH}+\mathrm{Pe}, \mathrm{M}=41.5, \mathrm{SE}=15.81 ;$ Figure 2). There was also a significant effect of age on the average vertical wingshakes $\left(\mathrm{F}_{3,4}=9.12, P\right.$ $=0.029)$. Pairwise comparisons indicated a significant increase in vertical wingshakes between weeks 2 and 3, but no significant differences between weeks 2,4 and 5 or weeks 3 , 4 and 5 (week $2, M=41.5, S E=9.86$; week $3, M=106.9, S E=21.11$; week $4, M=85.1, S E$ $=13.55 ;$ week $5, M=63.0, \mathrm{SE}=13.79$ ).

There was a positive correlation between the average number of birds present in the ring and the number of disturbance events recorded $(r(14)=0.88, P<0.001)$ and, in agreement with data from scan samples of behaviour, no significant difference in the number of birds counted in the $\mathrm{OH}$ compared to the $\mathrm{SB}+\mathrm{OH}$ during focal observations. There was no significant effect of the presence of straw bales on the level of disturbance in the oat hulls $(P$ $>0.05)$, however there were numerically fewer disturbed birds in the $\mathrm{SB}+\mathrm{OH}$ condition $(\mathrm{M}=$ 2.4, $\mathrm{SE}=0.65)$ compared to the $\mathrm{OH}$ alone $(\mathrm{M}=4.5, \mathrm{SE}=1.09)$. 


\subsection{Pecking Chain}

There was an average of $70(\mathrm{SE}=3.9)$ pecks directed at the pecking chain during the 10 minute focal period. The presence of other enrichments did not significantly affect the amount of chain pecking recorded $(P>0.05$; Figure 2$)$.

\section{Discussion}

The aim of this experiment was to determine whether grouping enrichments together would affect the way in which they were used, in order to look for any obvious benefits of creating "enrichment areas" over placing separate enrichments around the house. Contrary to expectations, the more complex enrichment areas did not appear to be more attractive to broilers. Whether enrichments were placed singly or in combinations did not have an effect on the number of broilers in the oat hulls or around the straw bales, or on the overall percentage of each behaviour observed. There was, however, significantly more vertical wingshaking recorded in the single dust baths compared to those placed with several other enrichments. As broilers aged there was a predictable effect on several behaviours, with an increase in inactivity and dustbathing in the oat hulls, and a reduction in pecking around the bales (Baxter et al., 2017; Baxter et al., 2018). There was also a positive correlation between the density of broilers using the oat hulls and the average number of birds being disturbed, which is consistent with previous trials (Hall, 2001; Buijs et al., 2010).

Laying hens will peck more readily at three types of pecking stimuli (string, beads and chain) when presented simultaneously compared to singly (Jones et al., 2000), which the authors suggest is because the varied stimuli are more attractive to birds. Our results suggest that grouping straw bales, oat hulls and pecking chain together did not increase the attractiveness of these enrichments. There was no increase in the number of broilers in the dustbathing areas or around the straw bales when they were placed in combination with other stimuli. There are several reasons why these enrichment areas may have failed to attract a higher number of birds than separately placed enrichments, although it is difficult to 
draw clear conclusions in this study. Unlike in Jones et al. (2000), where three types of the same pecking stimulus were presented, in the present trial the three different enrichments provided for different motivations. Oat hulls were attractive as a dustbathing substrate, while straw bales were largely used as a resting area, and the plastic-coated chain acted as an interactive pecking enrichment. The broilers may have been stimulated to use each enrichment regardless of nearby resources. It is also possible that broilers are less likely to engage with several enrichments when offered due to physical (Bessei, 2006) and motivational (Lindqvist et al., 2006) limitations. For example, an average foraging bout for broilers lasts only 3 minutes (Bizeray et al., 2002), which may only be directed at one type of enrichment before a period of rest. It is also possible that the enrichments were too far apart to act as a clustered set of diverse stimuli.

Overall, the types of behaviours observed around the straw bales and inside the rings were largely unaffected by grouping enrichments together. There was an effect of enrichment combination on the amount of dustbathing performed around the straw bales, with the presence of nearby oat hull rings influencing levels of dustbathing performed around the adjacent straw bales as birds aged. This effect was probably due to some oat hulls being kicked into the space in front of the bales or by visual contact with dustbathing birds in the nearby rings (Petherick et al., 1995). There were no differences in the amount of sitting, foraging, locomotion or preening when either straw bales or oat hulls were placed with other enrichments. Focal observations of the number of pecks directed at the straw bales and pecking chain, and the number of vertical wingshakes performed in the oat hulls were used to assess direct enrichment use. There was a significant interaction between enrichment combination and broiler age for the number of pecks directed at straw bales, however this effect was inconsistent and varied over time. Enrichment combination did not influence the number of pecks directed at the pecking chain throughout the cycle. For oat hull use, despite enrichment combination not influencing the percentage of broilers engaged in dustbathing bouts, focal observations revealed that significantly more vertical wingshakes were 
performed when oat hulls were placed individually $(\mathrm{OH}, \mathrm{M}=93.6)$ rather than with both other types of enrichment $(\mathrm{SB}+\mathrm{OH}+\mathrm{Pe}, \mathrm{M}=41.5)$. The amount of vertical wingshaking observed has previously been used to identify substrate preferences for dustbathing (e.g. Sanotra et al., 1995) and our results may indicate that broilers may prefer to dustbathe in oat hulls placed without nearby straw bales or pecking chain. This was contrary to our hypothesis that straw bales bordering the dustbathing areas would provide protective cover, which would lead to an increase in dustbathing and reduction in disturbances. Provision of vertical cover has been shown to increase the levels of dustbathing, resting and preening in broilers (Cornetto and Estevez, 2001; Newberry and Shackleton, 1997), probably because birds seek cover to perform behaviours that obscure their vision. Artificial cover has also been found to draw birds away from interior walls and reduce the overall levels of disturbance in a group (Cornetto et al., 2002). However, our observations showed no significant difference in the number of broilers jostled when dustbathing areas were bordered by straw bales. The straw bales used in the present trial $(0.4 \mathrm{~m}$ high, $0.4 \mathrm{~m}$ wide $)$ were not substantially smaller than cover panels $(0.61 \mathrm{~m}$ high, $0.61 \mathrm{~m}$ wide) used in previous experiments (Cornetto and Estevez, 2001). However, they may not have provided the extending vertical cover that birds show a preference for, for example the protection offered by trees and bushes (Dawkins et al. 2003). Straw bales may also have provided "obstructive" cover, which is less attractive than structures that provide partial concealment, possibly because opaque cover could conceal nearby predators (Newberry and Shackleton, 1997).

As broilers aged, levels of dustbathing and inactivity increased in the oat hulls and levels of sitting pecking increased around the straw bales, which is consistent with previous studies (Baxter et al., 2017; Baxter et al., 2018). The overall level of use of straw bales and oat hulls is comparable to previous research, with slightly less foraging in oat hulls in the present study (15-17\% of birds observed were foraging) compared to previous reports (27-29\%; Baxter et al., 2017; Baxter et al., 2018). The number of birds using the oat hulls for dustbathing appears to be fairly consistent, with $18-24 \%$ of birds observed dustbathing in the 
present trial and 13-19\% in previous studies (Baxter et al., 2017; Baxter et al., 2018). Of the limited amount of studies that have looked at straw bale use in commercially housed broilers, their differences in methodology, housing and bale type make it difficult to draw direct comparisons. Kells et al. (2001) and Bailie et al. (2013) used long-cut straw bales and plastic wrapped straw bales respectively, both counting the number of birds on one side of the bale and doubling it for analysis. Kells et al. (2001) counted any birds clustering around the bale within a $180^{\circ}$ angle, not specifying distance, and observed an average of 54 birds clustering around the bales in week 2, 22 in week 3 and 28 in week 4. Bailie et al. (2013) recorded birds $1 \mathrm{~m}$ distance from one side of the bale, reporting an average of 73 birds around the bales. They also found that birds were more likely to cluster around bales when provided with natural light in windowed housing which Kells et al. (2001) presumably did not use (not mentioned) and may explain the slightly lower numbers. In the present study, both sides of two adjacent bales were observed simultaneously, giving a more definite representation of the total number of birds around the bale. We observed an average of 30 birds within $0.5 \mathrm{~m}$ of the bales at any one time. It appears that birds are fairly consistent in their clustering around straw bales, suggesting they attract birds successfully in different systems and on different farms.

There was relatively high interest in the plastic chain, with an average of 70 pecks directed at the chain during the 10 minute observation period. White and yellow string has previously been identified as an attractive pecking stimulus for laying hens (Jones and Carmichael, 1998; Jones et al., 2000). However, when white string was offered to broilers housed in pens ( $2 \mathrm{~m}$ by $6 \mathrm{~m}$ ) in groups of 40 (with access to woodshavings and sand), only 42 pecks were directed to the string during a total of 28 hours of observation (Arnould et al., 2004). Bailie and O'Connell (2015) reported that broilers housed commercially had more interest in the string than previously thought, with a bout of pecking directed at white string occurring every 78 seconds. In agreement with a recent review of broiler enrichment research (Riber et al., 2017), it appears that more on-farm research of broiler enrichments is needed to confirm the 
results of smaller trials. The plastic chain supplied in this trial may also be a more practical enrichment for commercial broiler housing than, for example, string (Jones et al., 2000), because it can be washed and re-used between production cycles.

There seemed to be no negative effects of presenting birds with combinations of enrichments. In caged mice, presenting enrichments in a cluster rather than singly increased the amount of aggression, displacement of one animal using the enrichment by another, and stereotypic behaviours (Akre et al., 2011). Very little aggression was observed throughout the trial, which is consistent with previous findings (Mench, 1988; Pettit-Riley et al., 2002), and there was no increase in the amount of birds disturbed in combined enrichment areas. However, as commercial broiler houses contain a large number of animals, it is likely to be of more benefit to spread enrichments around the housing to impact more birds. We also found that placing bales in one area consistently throughout the trial led to an accumulation of dry straw in those specific areas, limiting the spread of fresh straw around the house. As enriched commercial farms can only supply a limited number of straw bales, distributing them evenly or in areas of wet litter may be more effective at maintaining litter condition.

\section{Conclusions}

In conclusion, there appeared to be no obvious benefits to clustering enrichments compared to offering them singly to birds. Grouping enrichments together did not appear to attract a higher number of birds to use the enrichments or clearly affect the majority of behaviours performed in enriched areas. Indeed, more vertical wingshaking was observed in singly placed dustbathing areas and we found some practical advantages to spreading enrichments evenly throughout the houses. Although birds grouped and rested around the straw bales, there were no significant "protective" effects of increased dustbathing or preening when bales were present around oat hulls, and no reduction in disturbances. Further large-scale research applying different enrichment combinations in different houses would be needed to look for overall effects on behaviour and productivity. Broilers did show 
significantly more interest in a pecking enrichment than has been reported previously, highlighting the need for more commercial scale research.

\section{Acknowledgments}

This project was jointly funded by the Department for Employment and Learning in Northern Ireland and by a research award from the World's Poultry Science Association - UK branch. The authors are grateful to Moy Park staff and the participating farmers for providing access to the farm and for their advice and support. The authors also wish to thank Padraig O'Carroll for his assistance in data collection.

\section{References}

Akre, A. K., Bakken, M., Hovland, A. L., Palme, R., \& Mason, G. (2011). Clustered environmental enrichments induce more aggression and stereotypic behaviour than do dispersed enrichments in female mice. Applied animal behaviour science, 131(3), 145152.

Arnould, C., Bizeray, D., Faure, J. M. and Leterrier, C. (2004). Effects of the addition of sand and string to pens on use of space, activity, tarsal angulations and bone composition in broiler chickens. Animal Welfare 13, 87-94.

Aviagen (2014). Ross Broiler Management Handbook. http://en.aviagen.com/assets /Tech Center/Ross Broiler/ Ross-Broiler-Handbook-2014i-EN.pdf (accessed 14 September 2018).

Bailie, C. L., Ball, M. E. E., and O'Connell, N. E. (2013). Influence of the provision of natural light and straw bales on activity levels and leg health in commercial broiler chickens. Animal, 7(04), 618-626.

Bailie, C. L., \& O'Connell, N. E. (2015). The influence of providing perches and string on activity levels, fearfulness and leg health in commercial broiler chickens. animal, 9(4), 660-668.

Baxter, M., Bailie, C. L., \& O'Connell, N. E. (2017). An evaluation of potential dustbathing substrates for commercial broiler chickens. Animal. Advanced online publication. doi.org/10.1017/S17 51731117003408

Baxter, M., Bailie, C. L., \& O'Connell, N. E. (2018). Evaluation of a dustbathing substrate and straw bales as environmental enrichments in commercial broiler housing. Applied Animal Behaviour Science, 200, 78-85. doi.org/10.1016/j.applanim.2017.11. 010

Bessei, W. (2006). Welfare of broilers: a review. World's Poultry Science Journal, 62(3), 455466. 
Bizeray, D., Leterrier, C., Constantin, P., Le Pape, G., \& Faure, J. M. (2002). Typology of activity bouts and effect of fearfulness on behaviour in meat-type chickens.

Behavioural processes, 58(1), 45-55.

Buijs, S., Keeling, L. J., Vangestel, C., Baert, J., Vangeyte, J., \& Tuyttens, F. A. M. (2010). Resting or hiding? Why broiler chickens stay near walls and how density affects this. Applied Animal Behaviour Science, 124(3), 97-103.

Chamove, A. S. (1989). Environmental enrichment: a review. Animal technology: journal of the Institute of Animal Technology. Available online:

https://awionline.org/content/environmental-enrichment-review (Accessed 20th Nov 2017).

CIWF (2017). Good Chicken Award. Retrieved from: https://www.compassioninfoodbusin ess.com/awards/good-chicken-award/eligibility-and-criteria/ (Accessed 10/08/2017).

Cornetto, T., \& Estevez, I. (2001). Influence of vertical panels on use of space by domestic fowl. Applied Animal Behaviour Science, 71(2), 141-153.

Cornetto, T., Estevez, I., \& Douglass, L. W. (2002). Using artificial cover to reduce aggression and disturbances in domestic fowl. Applied Animal Behaviour Science, 75(4), 325-336.

D’Eath, R. B., Arnott, G., Turner, S. P., Jensen, T., Lahrmann, H. P., Busch, M. E., ... \& Sandøe, P. (2014). Injurious tail biting in pigs: how can it be controlled in existing systems without tail docking?. animal, 8(9), 1479-1497.

Dawkins, M. S., Cook, P. A., Whittingham, M. J., Mansell, K. A., \& Harper, A. E. (2003). What makes free-range broiler chickens range? In situ measurement of habitat preference. Animal behaviour, 66(1), 151-160.

Douglas, C., Bateson, M., Walsh, C., Bédué, A., \& Edwards, S. A. (2012). Environmental enrichment induces optimistic cognitive biases in pigs. Applied Animal Behaviour Science, 139(1), 65-73.

El-Lethey, H., Aerni, V., Jungi, T. W., \& Wechsler, B. (2000). Stress and feather pecking in laying hens in relation to housing conditions. British poultry science, 41(1), 22-28.

Estevez, I. (1994). Efecto del tamano de grupo y de las condiciones de manejo en el compartamiento y uso del espacio del gallo domestico (Gallus gallus). Ph.D. Thesis, University of Cordoba, Spain.

Guy, J. H. \& Wright, A. N. (2003) Effect of enrichment with Pecka-Blocks ${ }^{\mathrm{TM}}$ on the behaviour and feather condition of commercially-reared broilers, British Poultry Science, 44:S1, 29-30, DOI: 10.1080/713655280.

Hall, A. L. (2001). The effect of stocking density on the welfare and behaviour of broiler chickens reared commercially. Animal Welfare, 10(1), 23-40.

Jones, R. B., \& Carmichael, N. L. (1998). Pecking at string by individually caged, adult laying hens: colour preferences and their stability. Applied Animal Behaviour Science, 60(1), $11-23$. 
Jones, R. B., Carmichael, N. L., \& Rayner, E. (2000). Pecking preferences and predispositions in domestic chicks: implications for the development of environmental enrichment devices. Applied Animal Behaviour Science, 69(4), 291-312.

Kells, A., Dawkins, M. S., \& Borja, M. C. (2001). The effect of a 'freedom food' enrichment on the behaviour of broilers on commercial farms. Animal Welfare, 10(4), 347-356.

Lindqvist, C., Zimmerman, P., \& Jensen, P. (2006). A note on contrafreeloading in broilers compared to layer chicks. Applied Animal Behaviour Science, 101(1), 161-166.

Mench, J. A. (1988). The development of aggressive behavior in male broiler chicks: A comparison with laying-type males and the effects of feed restriction. Applied Animal Behaviour Science, 21(3), 233-242.

Newberry, R. C. (1995). Environmental enrichment: increasing the biological relevance of captive environments. Applied Animal Behaviour Science, 44(2-4), 229-243.

Newberry, R. C. (1999). Exploratory behaviour of young domestic fowl. Applied animal behaviour science, 63(4), 311-321.

Newberry, R. C., \& Shackleton, D. M. (1997). Use of visual cover by domestic fowl: a Venetian blind effect?. Animal Behaviour, 54(2), 387-395.

Petherick, J. C., Seawright, E., Waddington, D., Duncan, I. J., and Murphy, L. B. (1995). The role of perception in the causation of dustbathing behaviour in domestic fowl. Animal Behaviour, 49(6), 1521-1530.

Pettit-Riley, R., Estevez, I., \& Russek-Cohen, E. (2002). Effects of crowding and access to perches on aggressive behaviour in broilers. Applied Animal Behaviour Science, 79(1), $11-25$.

Riber, A. B., van de Weerd, H. A., de Jong, I. C., \& Steenfeldt, S. (2017). Review of environmental enrichment for broiler chickens. Poultry Science, 97(2), 378-396. doi.org/10.338 2/ps/p ex344

Sanotra, G. S., Vestergaard, K. S., Agger, J. F., \& Lawson, L. G. (1995). The relative preferences for feathers, straw, wood-shavings and sand for dustbathing, pecking and scratching in domestic chicks. Applied Animal Behaviour Science, 43(4), 263-277.

Tahamtani, F. M., Brantsæter, M., Nordgreen, J., Sandberg, E., Hansen, T. B., Nødtvedt, A., Rodenburg, T. B., Moe, R. O. and Janczak, A. M. (2016). Effects of litter provision during early rearing and environmental enrichment during the production phase on feather pecking and feather damage in laying hens. Poultry science, 95(12), 27472756. 


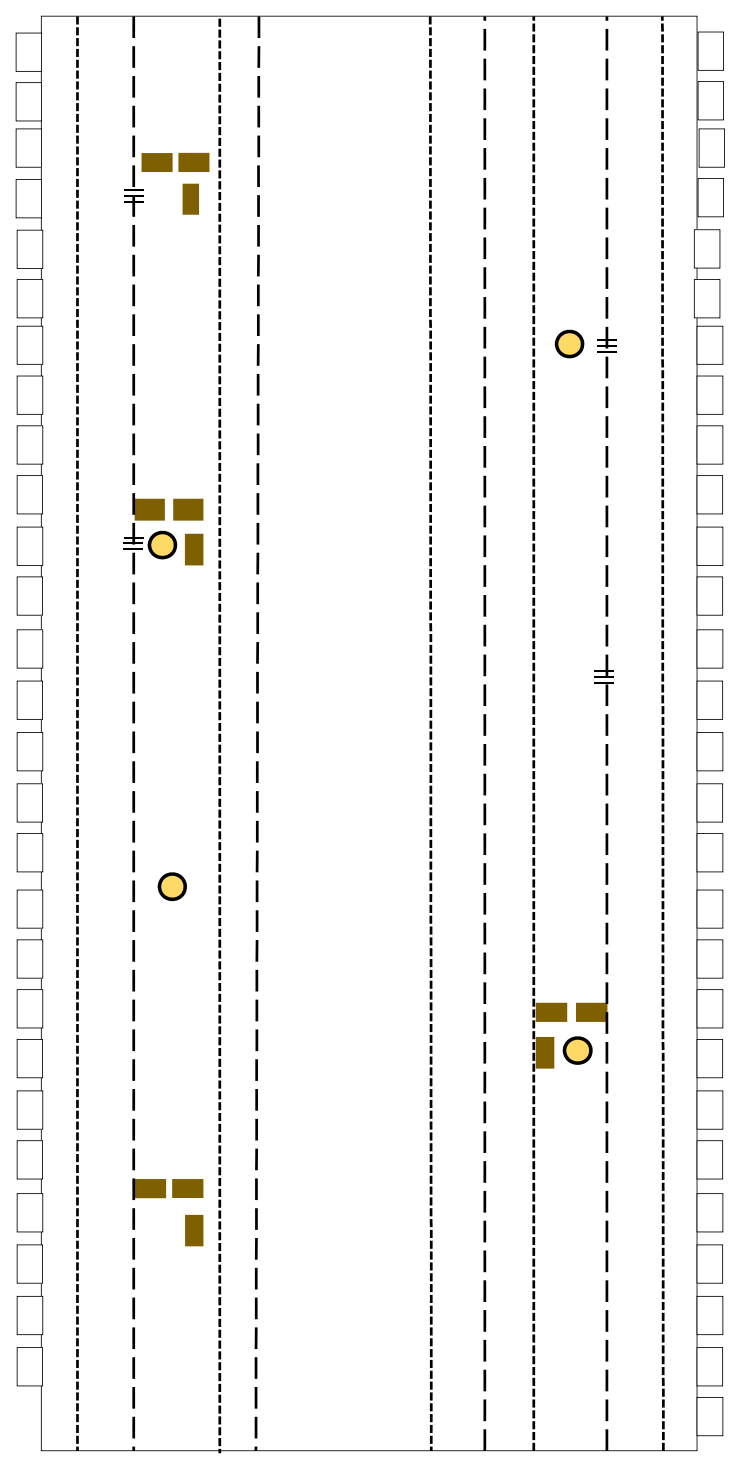

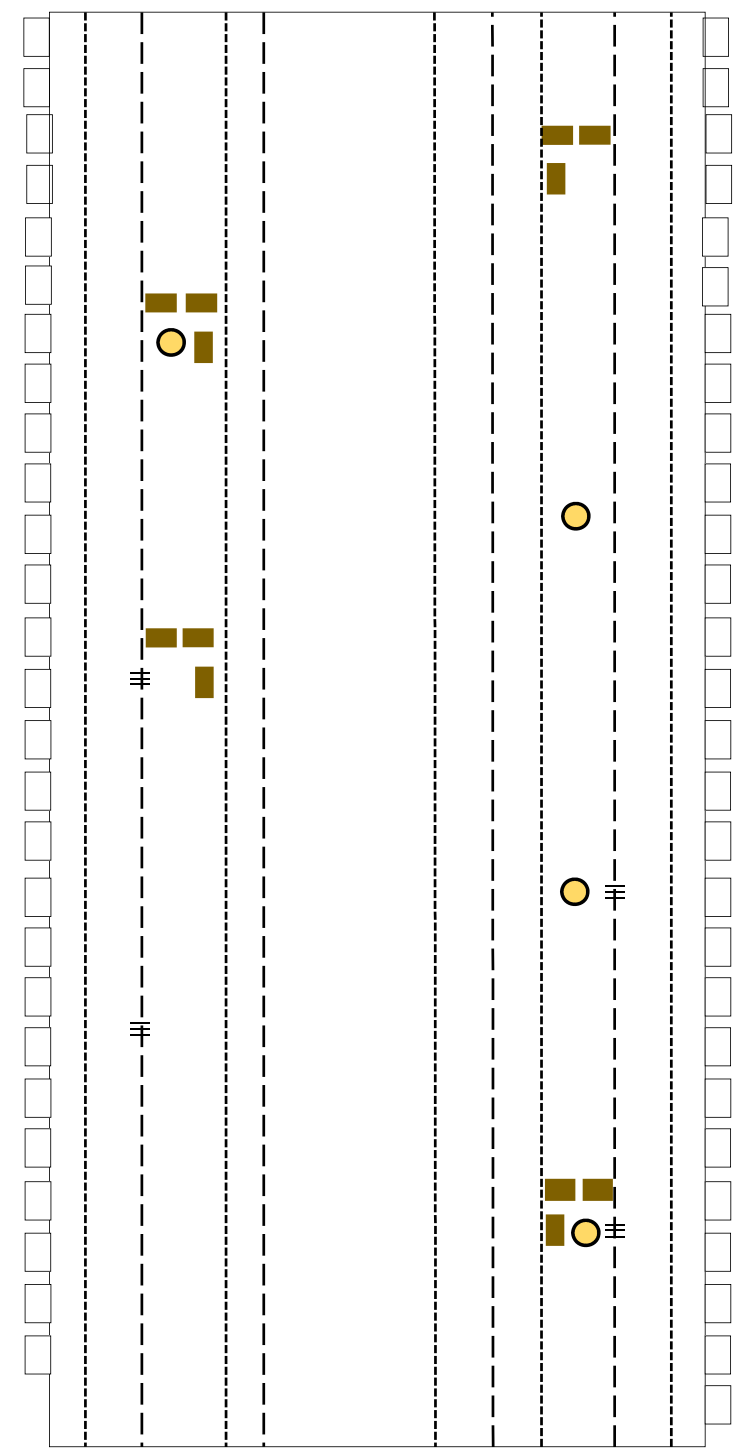

Figure 1. Placement of enrichment areas around matched houses. Vertical dotted lines represent nipple drinker lines; vertical dashed lines represent feeder lines. Boxes on the outer sides of the houses represent windows. The enrichments included were:

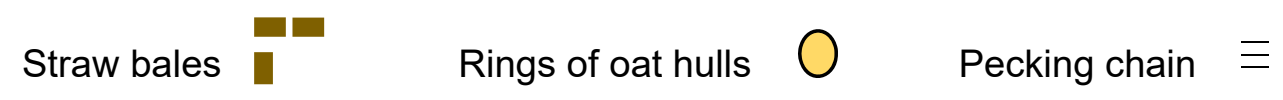

These enrichments were grouped into seven different enriched areas: 1) straw bales only, 2) oat hulls only, 3) pecking chain only, 4) straw bales and pecking chain, 5) oat hulls and pecking chain, 6) straw bales and oat hulls, 7) straw bales, oat hulls and pecking chain. 


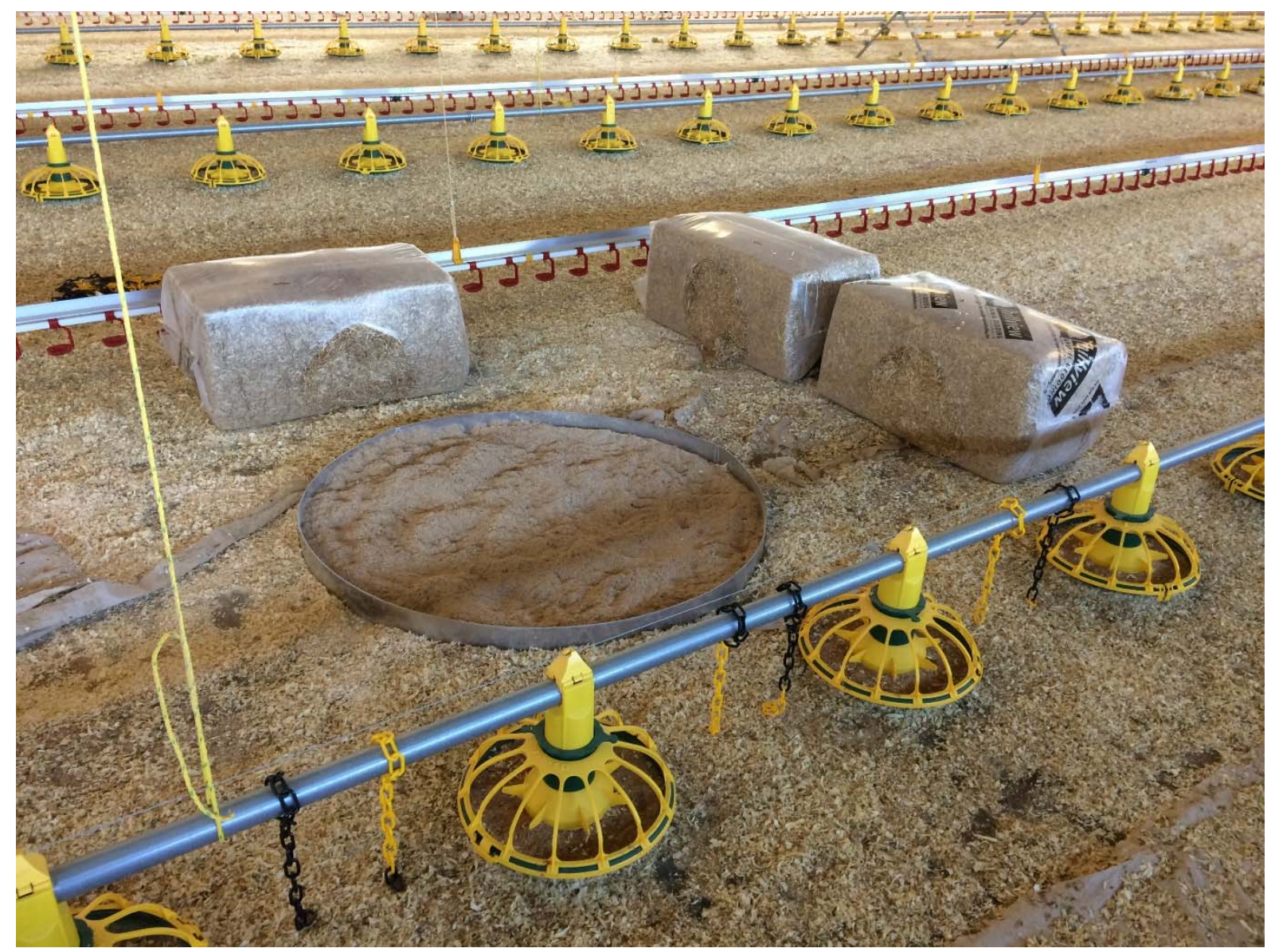

Photo 1. Photograph of enrichments placed in the $\mathrm{SB}+\mathrm{OH}+\mathrm{Pe}$ area (straw bales, oat hulls and pecking chain). Each individual enrichment placement represents the way enrichments are arranged in each combination, e.g. straw bales are arranged in an Lshape whether placed singly or in combination with other enrichments 


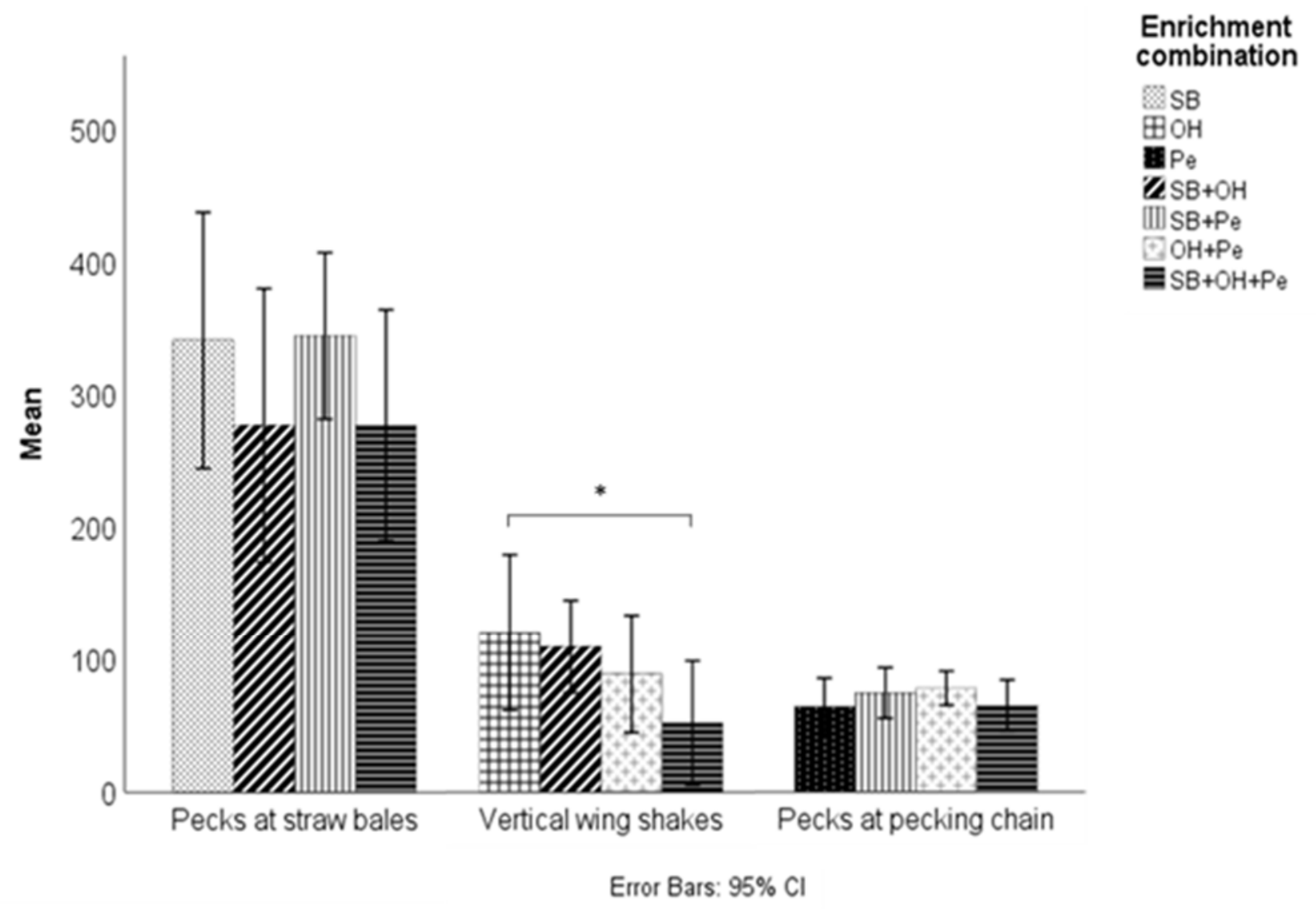

Figure 2. Focal observations of enrichment use. The average pecks directed at the straw bales when placed singly $(\mathrm{SB})$, with oat hulls $(\mathrm{SB}+\mathrm{OH})$, with pecking chain $(\mathrm{SB}+\mathrm{Pe})$, or with both oat hulls and pecking chain $(\mathrm{SB}+\mathrm{OH}+\mathrm{Pe})$. The number of vertical wingshakes performed in oat hulls when placed singly $(\mathrm{OH})$, with straw bales $(\mathrm{SB}+\mathrm{OH})$, with pecking chain $(\mathrm{OH}+\mathrm{Pe})$ or with both alternative enrichments $(\mathrm{SB}+\mathrm{OH}+\mathrm{Pe})$. And the number of pecks directed the pecking chain when placed singly $(\mathrm{Pe})$ and in various combinations with straw bales and oat hulls. ${ }^{*}$ denotes a significant difference $(P<0.05)$. 
Table 1. The behaviour of broilers using enrichments placed in each combination (mean $\% \pm$ standard error)

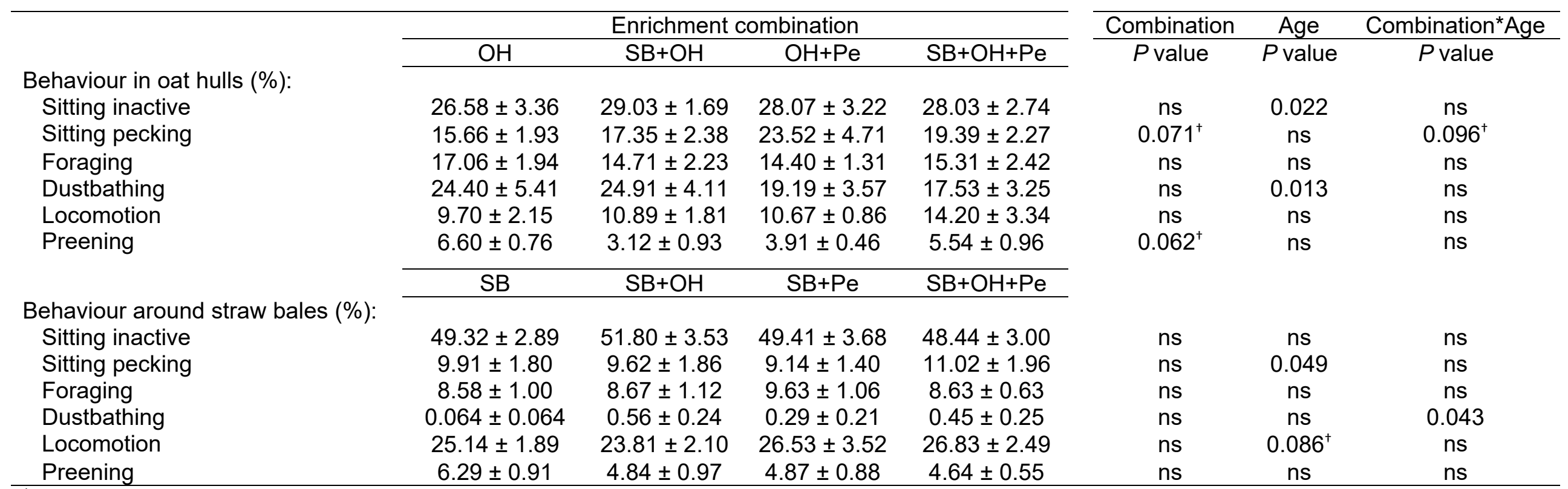

$\dagger P<0.1$. Analysed using GLM with "enrichment combination" and "week" as fixed factors and "house.week" as a random factor.

Oat hulls rings placed singly $(\mathrm{OH})$ with straw bales $(\mathrm{SB}+\mathrm{OH})$, with pecking chain $(\mathrm{OH}+\mathrm{Pe})$, or with straw bales, oat hulls and pecking chain

$(\mathrm{SB}+\mathrm{OH}+\mathrm{Pe})$; straw bales placed singly $(\mathrm{SB})$, with oat hulls $(\mathrm{SB}+\mathrm{OH})$, with pecking chain $(\mathrm{SB}+\mathrm{Pe})$, or with oat hulls and pecking chain

$(\mathrm{SB}+\mathrm{OH}+\mathrm{Pe})$. 